\title{
EL PROFESOR JOSEF OPATRNÝ RECIBE GALARDÓN DE LA UNIVERSIDAD CAROLINA EN SU SEPTUAGÉSIMO QUINTO CUMPLEAÑOS
}

El Prof. PhDr. Josef Opatrný, CSc., quien por casi cuatro decenios fue director del Centro de Estudios Ibero-Americanos de la Facultad de Filosofía de la Universidad Carolina fue galardonado, coincidiendo con la celebración de su aniversario (nació el 19 de noviembre de 1945), con una medalla de plata de la Universidad Carolina, concedida durante la sesión del Consejo Científico de la Universidad, el día 26 de noviembre de 2020. Este reconocimiento le fue otorgado por su vida académica dedicada a los estudios iberoamericanos y por sus méritos científicos y pedagógicos logrados en la misma Universidad.

Toda su carrera profesional ha estado ligada con la Universidad Carolina. Entre los años 1963 y 1968 estudió Historia y Checo en la Facultad de Filosofía. Su tesis de grado fue dedicada al final del dominio colonial de España en las islas Filipinas. Los temas del siglo XIX, la formación de las naciones, las relaciones entre América Latina y Estados Unidos, y entre América Latina y los países checos, continuarían siendo sus temas de profundización, ensanchándolos un tanto más allá, rumbo al pasado, como más acá, hacia el presente, alcanzando un panorama amplio y siempre actualizado.

Durante sus estudios de posgrado (1968 a 1971) se adhirió al grupo investigador que se empezaba a formar junto al naciente Centro de Estudios Ibero-Americanos, en donde colaboró muy estrechamente con su fundador y director del Centro durante muchos años, Prof. PhDr. Josef Polišenský, DrSc. Desde 1981 lo reemplazó en este cargo, llegando a ser, desde 1990, director de un departamento independiente, perteneciente a la Facultad de Filosofía, con su propia carrera en estudios iberoamericanos. ${ }^{1}$

\footnotetext{
Para una biografía más detallada de Josef Opatrný y su bibliografía hasta el año 2015 véase el volumen de homenaje dedicado a su 70 aniversario en la revista Dvacáté století $=$ The twentieth century 8/1 [on-line], Praha 2016, particularmente pp. 11-16 y 211-219 [consultado 20 de enero de 2021]. Accesible de: https://dvacatestoleti.ff.cuni.cz/magazin/2016-8-1/. Comp. también Simona BINKOVÁ - František VRHEL, "Josef Opatrný, Director del Centro de Estudios Ibero-Americanos, Sexagenario", Ibero-Americana Pragensia 39, 2005 (publ. 2006), pp. 11-21. Para las publicaciones más recientes ver el final de este texto. Sobre la evolución del Centro de Estudios Ibero-Americanos desde sus comienzos prometedores de finales de los años 60 y pasando por un período más difícil en los años 70 y 80 - en los que dependió del Departamento de Etnología - comp., p. ej., las memorias de Josef POLIŠENSKÝ, Historik v měnícím se světě [Historiador en un mundo cambiante], Praha 2001 , o varias contribuciones referentes al Centro publicadas en la revista Ibero-Americana Pragensia y en sus Supplementa. Para una evaluación de la trayectoria ver Josef OPATRNÝ, "Josef Polišenský y los principios de la iberoamericanística checa", Ibero-Americana Pragensia 45/2, 2017, pp. 19-27, o Markéta KŘÍŽOVÁ, "Josef Polišenský y su concepto de la historia general”, Ibero-Americana Pragensia 45/ 2, 2017, pp. 33-42, entre otros.
} 
En 1992, Josef Opatrný cumplió con los requisitos para obtener el grado de profesor asociado y en 1995 fue nombrado profesor catedrático. Luego de los mencionados casi cuatro decenios de dirección del Centro (hasta finales de 2018), continúa en su labor pedagógica, de investigación y divulgación, hasta hoy día.

Durante ese tiempo ha realizado numerosas estancias de investigación, ha publicado decenas de monografías (en español e inglés) y cientos de estudios; ha organizado cada año, con el esfuerzo propio, simposios científicos dedicados a la historia de las relaciones checo-latinoamericanas y a la historia del Caribe.

Junto con el Dr. Zidane Zeraoui (ITESSM, México) iniciaron los cursos de verano para los estudiantes del Tecnológico de Monterrey en la Universidad Carolina que se extendieron por veinte años ininterrumpidos, con la prevaleciente participación de la Dra. Luz Araceli González. El curso quedó estancado tan solo en el verano de 2020 y 2021, por la reciente pandemia de COVID-19.

El Prof. Opatrný dirige desde 1986 el anuario (hoy día revista semestral) Ibero-Americana Pragensia y su Supplementa (con periodicidad irregular) que en la actualidad constan de cincuenta títulos, cada una. Se le invita a participar en eventos internacionales como jurado y a presidir congresos científicos. Durante varios años fue vicepresidente de la Asociación de Historiadores-Latinoamericanistas Europeos (AHILA).

En 2002, su majestad Juan Carlos I, rey de España, le otorgó la Orden de Isabel la Católica en grado de Encomienda. Y en 2008, el mismo, la Encomienda de la Orden del Mérito Civil. En 2018, el gobierno de México le concedió la prestigiosa Orden de Águila Azteca.

El Prof. Opatrný también es reconocido por el gran público como autor de muchas obras de divulgación referentes a la historia de América Latina y EE. UU., así como diligente comentador de asuntos actuales en los medios de comunicación. Precisamente sus obras para el gran público checo merecieron en 2006 el Premio de Egon Erwin Kisch a la literatura de divulgación (concretamente, por el título Velká siouxská válka [La Gran Guerra de los Sioux] otorgado por la Sociedad de escritores checos [Obec spisovatelì] , y en los años 2005 y 2014 mereció el Premio de Miroslav Ivanov, otorgado por el Club de autores de la literatura de divulgación [Klub autorů literatury faktu], con la obra Stát osamělé hvězdy a mexicko-americká válka [El Estado de la estrella solitaria y la guerra entre México y EE. UU.] y Malá skvělá válka [La espléndida Guerra Chiquita], respectivamente.

Digno de mencionar, particularmente con ocasión de la entrega de la medalla de plata de la Universidad Carolina, es que gracias a su gestión se dio origen a los estudios de segundo ciclo y de doctorado en Iberoamericanística; formó a cientos de alumnos y participó y sigue participando en varios órganos de la Facultad y de la Universidad.

Valga mencionar su prolífica obra académica publicada. Recientemente ha entregado a la Editorial Karolinum una versión revisada y actualizada de su Amerika v proměnách století [América a través de los siglos].

por Simona Binková (Praga)

(Escrito en español por la autora) 


\section{BIBLIOGRAFÍA SELECTA DE JOSEF OPATRNÝ DESPUÉS DE $2015^{2}$}

\section{Monografías, monografías colectivas y volúmenes editados/coordinados}

2016

OPATRNÝ, Josef (coord.), Proyectos políticos y culturales en las realidades caribeñas de los siglos XIX y XX, Praga: Editorial Karolinum, 2016. 347 págs. ISBN 978-80-246-3267-4.

2017

OPATRNÝ, Josef (coord.), Las relaciones entre Europa Central y América Latina. Contextos históricos, Praga: Editorial Karolinum, 2017, 228 págs. ISBN 978-80-246-3553-8.

OPATRNÝ, Josef (coord.), Vida y obra de Juan Bosch en el contexto de la historia de la República Dominicana, Praga: Editorial Karolinum, 2017, 139 págs. ISBN 978-80-246-3533-0.

2018

OPATRNÝ, Josef (coord.), Caribe hispano y Europa. Siglos XIX y XX. Dos siglos de relaciones, Praga: Editorial Karolinum, 2018, 246 págs. ISBN 978-80-246-3816-4.

2019

OPATRNÝ, Josef, Estudios americanos, Santa Cruz de Tenerife: Ediciones Idea, 2019. 1090 págs.

ISBN 978-84-17764-50-0.

OPATRNÝ, Josef (coord.), Checoslovaquia, Europa Central y América Latina. El periodo de entreguerras, Praga, Editorial Karolinum, 2019, 178 págs. ISBN 978-80-246-4259-8.

2020

OPATRNÝ, Josef - Simona BINKOVÁ (coords.), Quinientos años de La Habana (1519-2019). Colonialismo, nacionalismo, internacionalismo, Praga: Editorial Karolinum, 2020, 309 págs.

ISBN 978-80-246-4504-9.

\section{Estudios y artículos científicos, capítulos en monografías}

2016

OPATRNÝ, Josef, "Historische Grundlagen der tschechoslowakisch-lateinamerikanischen Beziehungen zwischen 1945-1989”, in: Albert Manke - Kateřina Březinová (eds.), Kleinstaaten und sekundäre Akteure im Kalten Krieg, Bielefeld: Transcript Verlaq, 2016, pp. 83-104. ISBN 978-3-8376-3526-3.

OPATRNÝ, Josef, "Domingo del Monte en la discusión sobre la trata y esclavitud", in: Josef Opatrný (coord.), Proyectos políticos y culturales en las realidades caribeñas de los siglos XIX y XX, Praga: Editorial Karolinum, 2016, pp. 167-181. ISBN 978-80-246-3267-4.

2017

OPATRNÝ, Josef, “Španělsko, občanská válka a atlantický svět”, in: Emil Voráček - Zdenko Maršálek (eds.), Interbrigadisté, Československo a španělská občanská válka [Interbrigadistas, Checoslovaquia y la Guerra Civil Española], Praha: Historický ústav AV ČR, 2017, pp. 10-33. ISBN 978-80-7286-312-9.

OPATRNÝ, Josef, "Desde la emigración austrohúngara hasta los partidarios del Estado independiente checoslovaco en Argentina", in: Ursula Prutsch - João Fábio Bertonha - Mónika Szente-Varga (coords.), Aventureros, utopistas, emigrantes. Del Imperio Habsburgo a las Américas, Frankfurt am Main: Iberoamericana Vervuert, 2017, pp. 159-174. ISBN 978-84-16922-30-7.

OPATRNÝ, Josef, “Eva Perónová (1919-1952)”, in: Miroslav Bárta - Martin Kovář (eds.): Lidé a dějiny [Gente e historia], Praha: Academia, 2017, pp. 741-762. ISBN 978-80-200-2716-0.

OPATRNÝ, Josef, "El siglo XX en las relaciones checo-dominicanas", in: idem (coord.), Vida y obra de Juan Bosch en el contexto de la historia de la República Dominicana, Praga: Editorial Karolinum, 2017, pp. 93-111. ISBN 978-80-7277-558-3.

2 Se enumeran las publicaciones posteriores a las mencionadas en las referencias de la nota 1. 
OPATRNÝ, Josef, "Cinco siglos de las relaciones entre los Países Checos y América Latina”, in: idem (coord.): Las relaciones entre Europa Central y América Latina: contextos históricos, Praga: Editorial Karolinum, 2017, pp. 17-40. ISBN 978-80-246-3553-8.

OPATRNÝ, Josef, "Josef Polišenský y los principios de la iberoamericanística checa", Ibero-Americana Pragensia 45/2, 2017, pp. 23-31. ISSN 0536-2520.

2018

OPATRNÝ, Josef, "Checoslovaquia y Caribe hispano en los cincuenta y sesenta del siglo XX", in: idem (coord.), Caribe hispano y Europa. Siglos XIX y XX. Dos siglos de relaciones, Praga: Editorial Karolinum, 2018, pp. 169-185. ISBN 978-80-246-3816-4.

OPATRNÝ, Josef - Sigfrido VÁZQUEZ CIENFUEGOS, "Cuba y Checoslovaquia durante la Guerra Fría en las fuentes checoslovacas: Estudio de caso", in: José Manuel Azcona Pastor - José Manuel Escalona Chádez - Mónica García Salgado (eds.), Relaciones bilaterales España-Cuba (siglo XX), Madrid: Sílex Universidad, 2018, pp. 511-544. ISBN 978-84-7737-931-7.

2019

OPATRNÝ, Josef, "América Latina en los textos de emigrantes y viajeros checos en los años veinte y treinta del siglo XX", in: idem (coord.), Checoslovaquia, Europa Central y América Latina. El periodo de entreguerras, Praga: Editorial Karolinum, 2019, pp. 137-154. ISBN 978-80-246-4259-8.

OPATRNÝ, Josef, "The Long Road to Collapse. The End of an Empire on Which the Sun Never Set", in: Miroslav Bárta - Martin Kováŕ (eds.): Civilisations: Collapse and regenerations. Rise, fall and transformation in history, Prague: Academia, 2019, pp. 393-436. ISBN 978-80-200-2907-2.

OPATRNÝ, Josef, "La sociedad de Bohemia del siglo XIX y la guerra hispano-americana", in: José Girón Garrote (dir.), España y Estados Unidos en 1898. La guerra a través de la prensa europea, Oviedo: Universidad de Oviedo, 2019, pp. 67-78. ISBN 978-84-16343-79-9.

2020

OPATRNÝ, Josef, "La Habana en los textos de los visitantes checos durante el siglo XX", in: OPATRNÝ, Josef - Simona BINKOVÁ (coords.), Quinientos años de La Habana (1519-2019). Colonialismo, nacionalismo, internacionalismo, Praga: Editorial Karolinum, 2020, pp. 129-138.

ISBN 978-80-246-4504-9.

\section{Obras de divulgación - monografías}

OPATRNÝ, Josef, Mexiko [México], 2a ed. actualizada, Praha: Libri, 2016, 227 págs. ISBN 978-80-7277-548-4.

OPATRNÝ, Josef, Válka Severu proti Jihu [Guerra de Secesión], Praha: Vydavatelství Karolinum, 2017, 385 págs. ISBN 978-80-246-3553-8.

OPATRNÝ,Josef,Kuba [Cuba],2 2a ed. actualizada,Praha: Libri, 2017, 196 págs. ISBN 978-80-7277-558-3.

OPATRNÝ, Josef, Splněný sen majora Rogerse. Lewis a Clark na březích Pacifiku [El sueño de mayor Rogers se hizo realidad. Lewis y Clark en las costas del Pacífico], Praha: Epocha, 2017, 170 págs. ISBN 978-80-7557-071-0.

OPATRNÝ, Josef, Panama [Panamá], 2ª ed. actualizada, Praha: Libri, 2019, 195 págs. ISBN 978-80-7277-575-0.

OPATRNÝ, Josef, Lid mi ř́ká Evita. Životní př́běh Evy Perónové [El pueblo me llama Evita. La historia de vida de Eva Perón], Praha: Nakladatelství Epocha, 2019, 315 págs. ISBN 978-80-7557-223-3.

OPATRNÝ, Josef, Amerika presidenta Granta [América del presidente Grant], Praha: Nakladatelství Karolinum, 2019, 431 págs. ISBN 978-80-246-4191-1.

\section{Obras de divulgación - artículos}

OPATRNÝ, Josef, "Nezávislost Argentiny" [La independencia de Argentina], PLAV: měsičník pro světovou literaturu 2, 2016, pp. 2-3. ISSN 1802-4734.

OPATRNÝ, Josef, "Tři století česko-argentinských vztahů" [Tres siglos de las relaciones checo-argentinas], PLAV: měsíčník pro světovou literaturu 2, 2016, pp. 4-8. ISSN 1802-4734. 
OPATRNÝ, Josef, “Dějiny ho zprostí viny?” [¿La historia le absolverá?], Dějiny a současnost 9, 2017, pp. 15-19. ISSN 0418-5129.

OPATRNÝ, Josef, “Cesta na severozápad” [Camino al noroeste], Živá historie 10, 2017, pp. 15-19. ISSN 1803-3326.

OPATRNÝ, Josef, "Na Klondiku je zlato!” [¡En Klondike hay oro!], Živá historie 3, 2018, pp. 14-17. ISSN 1803-3326.

OPATRNÝ, Josef, "Ocelový oř mezi oceány" [Caballo de hierro entre los océanos], Živá historie 9 , 2018, pp. 18-21. ISSN 1803-3326.

OPATRNÝ, Josef, "Nesmiřitelný rudý lupič a vrah" [El implacable piel roja ladrón y asesino], Živá historie 10, 2018, pp. 26-29. ISSN 1803-3326.

OPATRNÝ, Josef, "Bitva na Abrahámových pláních” [Batalla de las Llanuras de Abraham], Živá historie 1-2, 2019, pp. 18-23. ISSN 1803-3326.

OPATRNÝ, Josef, "Nikdy nespíme" [No dormimos nunca], Živá historie 10, 2019, pp. 30-34. ISSN 1803-3326.

OPATRNÝ, Josef, "Poprvé kolem světa. 1519-1522 Magalhãesova výprava” [La primera vez alrededor del mundo. 1519-1522 La expedición de Magalhães], Živá historie 12, 2019, pp. 35-39.

ISSN 1803-3326.

OPATRNÝ, Josef, “1492 Objevení Ameriky” [1492 El descubrimiento de América], Kauzy - Extra historie 39, 2019, pp. 6-50. ISSN 1805-0301.

OPATRNÝ, Josef, "Nesmrtelná ikona Argentiny" [El ícono inmortal de Argentina], Živá historie 1-2, 2020, pp. 16-20. ISSN 1803-3326.

OPATRNÝ, Josef, "Po stopách revolucionáře" [En pos de un revolucionario], Tajemství české minulosti 85, 2020, pp. 44-50, ISSN 1804-2260.

OPATRNÝ, Josef, "Manhattan za 60 guldenů" [Manhattan por 60 florines], Živá historie 3, 2020, pp. 26-29. ISSN 1803-3326.

OPATRNÝ, Josef, "Hlavní cíl: jižní polokoule" [La meta principal: el hemisferio sur], Živá historie 7-8, 2020, pp. 8-13. ISSN 1803-3326.

OPATRNÝ, Josef, “Zařený sen o Patagonii” [Patagonia, un sueño fracasado], Tajemství české minulosti 87, 2020, pp. 76-81. ISSN 1804-2260.

OPATRNÝ, Josef, “Kolumbijská hrdinka La Pola” [La heroína llamada La Pola], Živá historie 9, 2020, pp. 76-79, ISSN 1803-3326.

OPATRNÝ, Josef, “Tahle země není pro černé” [Este país no es para los negros], Živá historie 10, 2020, pp. 42-47, ISSN 1803-3326.

\section{Otros $^{3}$}

OPATRNÝ, Josef, "Recordando a Bohumil Badura”, Ibero-Americana Pragensia 45/1, 2017, pp. 15-19. ISSN 0536-2520 (necrología).

OPATRNÝ, Josef, “Ádám Anderle in memoriam”, Ibero-Americana Pragensia 46/2, 2019, pp. 7-11. ISSN 0536-2520 (necrología).

OPATRNÝ, Josef, "Richard Halliburton ve světě bez hranic" [Richard Halliburton en un mundo sin fronteras], in: Richard Halliburton, Po stopách dobrodruha. Hana Bortlová-Vondráková (trad. y ed.), Praha: Regia, 2019, pp. 5-7. ISBN 978-80-87866-42-9 (introducción).

OPATRNÝ, Josef, "Hideaki Kami, Diplomacy meets migration". Journal of American History 106/1, June 2019, pp. 248-249. ISSN 0021-8723 (reseña).

OPATRNÝ, Josef, "Lisandro Pérez, Sugar, Cigars, and Revolution. The Making of Cuban New York", Ibero-Americana Pragensia 46/2, 2019, pp. 76-77. ISSN 0536-2520 (reseña).

3 Prescindimos aquí de reseñas publicadas en lengua checa en revistas checas. 